NASA/TM-2005-213639

\title{
Parametric Investigation of Liquid Jets in Low Gravity
}

David J. Chato

Glenn Research Center, Cleveland, Ohio 
Since its founding, NASA has been dedicated to the advancement of aeronautics and space science. The NASA Scientific and Technical Information (STI) Program Office plays a key part in helping NASA maintain this important role.

The NASA STI Program Office is operated by Langley Research Center, the Lead Center for NASA's scientific and technical information. The NASA STI Program Office provides access to the NASA STI Database, the largest collection of aeronautical and space science STI in the world. The Program Office is also NASA's institutional mechanism for disseminating the results of its research and development activities. These results are published by NASA in the NASA STI Report Series, which includes the following report types:

- TECHNICAL PUBLICATION. Reports of completed research or a major significant phase of research that present the results of NASA programs and include extensive data or theoretical analysis. Includes compilations of significant scientific and technical data and information deemed to be of continuing reference value. NASA's counterpart of peerreviewed formal professional papers but has less stringent limitations on manuscript length and extent of graphic presentations.

- TECHNICAL MEMORANDUM. Scientific and technical findings that are preliminary or of specialized interest, e.g., quick release reports, working papers, and bibliographies that contain minimal annotation. Does not contain extensive analysis.

- CONTRACTOR REPORT. Scientific and technical findings by NASA-sponsored contractors and grantees.
- CONFERENCE PUBLICATION. Collected papers from scientific and technical conferences, symposia, seminars, or other meetings sponsored or cosponsored by NASA.

- SPECIAL PUBLICATION. Scientific, technical, or historical information from NASA programs, projects, and missions, often concerned with subjects having substantial public interest.

- TECHNICAL TRANSLATION. Englishlanguage translations of foreign scientific and technical material pertinent to NASA's mission.

Specialized services that complement the STI Program Office's diverse offerings include creating custom thesauri, building customized databases, organizing and publishing research results ... even providing videos.

For more information about the NASA STI Program Office, see the following:

- Access the NASA STI Program Home Page at http://www.sti.nasa.gov

- E-mail your question via the Internet to help@sti.nasa.gov

- Fax your question to the NASA Access Help Desk at 301-621-0134

- Telephone the NASA Access Help Desk at 301-621-0390

- Write to:

NASA Access Help Desk

NASA Center for AeroSpace Information 7121 Standard Drive

Hanover, MD 21076 
NASA/TM-2005-213639

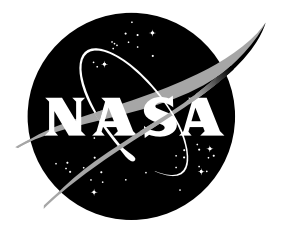

\section{Parametric Investigation of Liquid Jets in Low Gravity}

David J. Chato

Glenn Research Center, Cleveland, Ohio

Prepared for the

41st Aerospace Sciences Meeting and Exhibit

sponsored by the American Institute of Aeronautics and Astronautics

Reno, Nevada, January 6-9, 2003

National Aeronautics and

Space Administration

Glenn Research Center 
Available from

NASA Center for Aerospace Information 7121 Standard Drive

Hanover, MD 21076
National Technical Information Service 5285 Port Royal Road Springfield, VA 22100

Available electronically at http://gltrs.grc.nasa.gov 


\title{
Parametric Investigation of Liquid Jets in Low Gravity
}

\author{
David J. Chato \\ National Aeronautics and Space Administration \\ Glenn Research Center \\ Cleveland, Ohio 44135
}

\begin{abstract}
An axisymetric phase field model is developed and used to model surface tension forces on liquid jets in microgravity. The previous work in this area is reviewed and a baseline drop tower experiment selected for model comparison. This paper uses the model to parametrically investigate the influence of key parameters on the geysers formed by jets in microgravity. Investigation of the contact angle showed the expected trend of increasing contact angle increasing geyser height. Investigation of the tank radius showed some interesting effects and demonstrated the zone of free surface deformation is quite large. Variation of the surface tension with a laminar jet showed clearly the evolution of free surface shape with Weber number. It predicted a breakthrough Weber number of 1 .
\end{abstract}

\section{Nomenclature}

$\begin{array}{ll}W e & \text { Weber number }=\frac{\rho u_{a v}{ }^{2} r}{2 \sigma} \\ \rho & \text { density } \\ U & \text { velocity } \\ u_{a v} & \text { average jet velocity } \\ r & \text { jet radius } \\ \sigma & \text { surface tension } \\ f & \text { free energy } \\ \alpha & \text { constant } 1 \\ \beta & \text { constant 2 } \\ C & \text { phase distribution } \\ \psi & \text { barrier function } \\ V & \text { volume } \\ \phi & \text { potential function } \\ P & \text { pressure } \\ x & \text { distance } \\ g & \text { wall function } \\ M & \text { radial correction factor } \\ \theta_{c} & \text { contact angle } \\ a & \text { height } \\ d & \text { jet diameter } \\ D & \text { tank diameter } \\ L & \text { tank length } \\ R e & \text { Reynolds Number }=\frac{\rho u_{a v} d}{\mu} \\ & \end{array}$

\section{Introduction}

Microgravity poses many challenges to the designer of fluid storage for spacecraft. Chief among these are the lack of phase separation in the fluid and the need to supply vapor-free liquid or liquid-free vapor to the required spacecraft processes. One of the principal causes of lack of phase separation is the creation of liquid jets. A jet can be created by liquid filling, settling of the fluid to one end of the tank, or even closing a valve to stop the liquid outflow. In normal gravity the gravitational force controls and restricts the liquid jet flow, but in microgravity jets must be contained by surface tension forces. Recent NASA experiments in microgravity ${ }^{1-6}$ have brought a wealth of data of jet behavior in microgravity. The Vented Tank ResupplyExperiment ${ }^{6}$ was surprising in that although it contained a complex geometry of baffles and vanes the limit on liquid inflow was the emergence of a liquid jet from the top of the vane structure. Clearly understanding the restraint of liquid jets by surface tension is key to managing fluids in low gravity.

Flow of a submerged axial jet constrained by surface tension in low gravity is similar to stagnation flow against a plate in that the jet hits the constraining surface and is deflected radially out. However, in low gravity the ability of the constraining surface to move in response to the exerted force is unique. In fact to increase the restraining force on the jet as flow rate increases, the surface must deform to decrease the radius of curvature of the free surface, thereby increasing the surface tension force. Eventually the limit is reached where the radius curvature required is sufficiently smaller than the jet diameter such that it can no longer restrain the jet. When the deformation of the free surface is large the restraining bulge is long and slender. At this point several other mechanisms act to break down the jet, such as columnar buckling or the Taylor Instability where surface waves grow to such amplitude that they pinch a droplet off from the jet.

To model this low gravity phenomenon a numerical method that tracks the fluid motion and the surface tension forces is required. Jacqmin ${ }^{7}$ has developed a phase-field model that converts the delta-function surface tension force into a continuum function that peaks at the free surface and decays rapidly away. Previous attempts at this formulation have been criticized for smearing the interface but by sharpening the phase function, double gridding the 
fluid function and using a higher order solution for the fluid function these concerns have been ameliorated.

\section{Review of Literature}

NASA Drop Tower Data is found in references 8 to 19 . Symons $^{8-11}$ and Spuckler ${ }^{13}$ studied the liquid inflow via axial jet into a broad range of tank shapes both empty and partially full. Symons' work establishes an empirical limit for jets of Weber number (We) equal to 1.3-1.5 depending on jet velocity profile, where:

$$
W e=\frac{\rho u_{a v}{ }^{2} r}{2 \sigma}
$$

Staskus $^{12}$ extends the work of Symons by placing baffles in front of the jet. However, no attempt is made to analyze these complex flows. Instead results are reported as a ratio of improvement to the unbaffled jet Weber number. Labus ${ }^{14}$ also studies the effect of baffles including ones that break the central jet into several small jets. Aydelott ${ }^{16,18-19}$ looks at the problem of a recirculating jet where the liquid level is held constant. Results are classified into four flow patterns, dissipation, geyser formation, aft collection, and circulation. It is the geyser formation/aft collection we concern ourselves with in this paper. Aydelott's assessment that a drop in mixing accompanies this transition indicates the transition's importance. Labus ${ }^{17}$ studies both stagnation flow and free surface shape, but is concerned with the free surface of the back side of a liquid jet stagnated against a flat plate in microgravity.

Shuttle based experiments in references 1 to 6 provide valuable low gravity data. Video of Plexiglas tanks during shuttle orbital flight provide several improvements over drop tower tests; including increasing the scale from 4 to 12 inch tanks and extending the duration of test from 5 seconds to half-an-hour. Tank Pressure Control Experiment has flown three times. The first flight focused on the mixing studies of Aydelott. Advances over Aydelott included actual heat transfer data by using a condensing fluid (refrigerant 113) and longer duration. Bentz ${ }^{1-3}$ was able to confirm the geysering and circulating regimes of Aydelott, but encountered an asymmetric regime between the two that was even lower heat transfer than aft collection, the lowest heat transfer regime of Aydelott. The second flight of TPCE focused mostly on rapid boiling phenomena, but contains some further tests on mixing. Hasan ${ }^{4}$ confirms the findings of Bentz. The third flight ${ }^{5}$ was done at a lower fill level but confirms the results of the other flights. The Vented Tank Resupply Experment $^{6}$ was designed to look at vanes rather than axial jets, but as noted previously exhibits the classic gesyering behavior.
Analytical work is listed in reference 7 and references 20 to 31 . Concus ${ }^{20-21}$ provides differential equations of the free surface problem, but analyzes only static cases. Nickell $^{22}$ analyzes flow from a jet into a liquid and the resultant free surface shape for a normal gravity application, but removes all surface tension from the analysis as secondary. Hochstein ${ }^{23-24}$ analyzes the microgravity mixing with a volume of fluid approach, but uses only a limited approximation to model the surface tension. Aydelott ${ }^{25}$ and Der $^{26}$ both analyze the motion of a bubble in the oxygen tank during separation of a Centaur stage with VOF models; noteworthy in these is again the appearance of a geyser. Tegart ${ }^{27}$ shows the application of the surface Evolver code of Brakke ${ }^{28}$ to actual tank shapes. Brackbill $^{29}$ develops an improved surface tension model for VOF codes, but only shows one example of its use for axial jets. Shrader ${ }^{30}$ uses a Runga-Kutta scheme to solve the differential equation of free surface deformation in response to an imposed pressure field. This approach is quite promising but does not always converge and limits the interaction between the flow field and the free surface. Jacqmin $^{7}$ developed a phase field model of surface tension and implemented as a fourth order accurate scheme using a compact 9-point stencil. Although Jacqmin lays out the basic axisymmetric scheme the computer code and all the examples in his paper are planar. The Jacqmin model will serve as the basis for the present analysis.

\section{Model}

\section{Introduction}

To model the fluid motion the Navier-Stokes equations are formulated for low-speed incompressible flow. This paper will document the adaptation of the Jacqmin algorithm to the problem of restraint of liquid jets. Velocity and pressure are placed on a staggered grid, with velocity being tracked at cell faces and pressure at cell centers. To track the free surface a color function is introduced which tracks liquid as $1 / 2$ and gas as $-1 / 2$. Enhancements to the Jacqmin model include formulation of an axisymmetric fourth order model, implementation of a symmetric boundary condition at the tank centerline, and extension of the wall wetting boundary condition to fourth order accuracy. A simple velocity forcing function has been added to simulate the jet without violating continuity.

\section{Phase Model of Surface Tension}

Surface tension can be expressed as a free energy field. The expression for this energy in our formulation is given by

$$
f \quad \frac{1}{2}|C|^{2}
$$


where $\mathrm{C}$ is a phase distribution function and $\psi$ is a barrier function that is maximum at the interface and dies away as the phase becomes uniform. This formulation is extracted from Van der Waals $^{31}$ and inherently implies that the equilibrium free surface position is the one where the free energy is minimized. In order to model this behavior the physical $\psi$ that dies away on the molecular scale is approximated by a function with similar behavior on a larger scale such as

$$
\Psi(C)=\frac{2^{2 k}}{2 k+2} C^{2 k+2}-\frac{1}{2} C^{2}+\frac{2 k}{8(2 k+2)}
$$

This function has the required properties of being maximum at $C=0$ and dying away to 0 at both $1 / 2$ and $-1 / 2$. If we define our $C$ function as being $1 / 2$ when the phase is liquid and $-1 / 2$ when the phase is gas this will produce the required behavior. Higher values of $k$ produce sharper peaks. For our solution we will choose $k=16$.

To study the transients of the free surface some additional formulations are required. We define a potential function as the rate of change in $f$ per unit volume with respect to $\mathrm{C}$.

$$
\phi=\frac{\delta \int f d V}{\delta C}=\beta \Psi^{\prime}(C)-\alpha \nabla^{2} C
$$

Cahn and Hilliard ${ }^{32}$ approximate the transients of the free surface by setting the diffusion fluxes as proportional to the potential gradient. In equation form this is

$$
\frac{\partial C}{\partial t}=\kappa \nabla^{2} \phi
$$

This gives us two coupled Possion equations to solve for the phase distribution. To add the effects of fluid motion we must use the Navier-Stokes equations. The continuity equation for incompressible flow is

$$
\vec{\nabla} \bullet \vec{u}=0
$$

The momentum equations for each direction are given by

$$
\begin{aligned}
& \rho \frac{D u_{i}}{D t}=\rho \frac{\partial u_{i}}{\partial t}+\rho \sum_{j} u_{j} \frac{\partial u_{i}}{\partial x_{j}}= \\
& -\vec{\nabla} P+\mu \nabla^{2} u_{i}-C \vec{\nabla} \phi
\end{aligned}
$$

\section{Fourth Order Formulation of the Governing Equations}

The equations of the previous section cannot be solved directly but must be solved numerically. To keep the interface as sharp as possible a compact $4^{\text {th }}$ order stencil is used. Details of the stencil formulation can be found in Chato. ${ }^{34}$ The main computational stencil in the regular cylindrical co-ordinates used for this study is

$$
\begin{aligned}
& \frac{\alpha}{6(\Delta x)^{2}}\left[\begin{array}{ccc}
M_{-} & 4 & M_{+} \\
4 M_{-} & -20 & 4 M_{+} \\
M_{-} & 4 & M_{+}
\end{array}\right] C= \\
& \frac{\beta}{12}\left[\begin{array}{ccc}
0 & 1 & 0 \\
M_{-} & 8 & M_{+} \\
0 & 1 & 0
\end{array}\right] \Psi^{\prime}(C) \\
& -\left[\begin{array}{lll}
0 & 0 & 0 \\
0 & 1 & 0 \\
0 & 0 & 0
\end{array}\right] \phi+\frac{(\Delta r)^{2}}{12} \nabla^{2} \phi+O\left(\Delta r^{4}\right)
\end{aligned}
$$

where

$$
M_{ \pm}=\left(r_{ \pm}+r_{0}\right) / 2 r_{0}
$$

Chato $^{33}$ derives modifications for the stencil at each boundary of the computational domain including: a symmetry boundary at the inner edge, 90 degree contact angle boundaries at the top and bottom edges, and a variable contact angle boundary on the outer edge.

\section{Implementation as a CFD code}

The previous equations form a complete set of differential equations that can be solved for the fluid transient motion. Each equation is solved sequentially and numeric techniques specific to each equation are used to achieve the desired level of accuracy.

Solution for the potential field.-A Newton-Rhapson iteration is used to project the body centered values of $\mathrm{C}$ to the cell boundaries and produce a $\phi$ field consistent with equation (5).

Advection of phase quantities.-The equation (8) and its boundary equations form a matrix equation that is solved using the current values of $\mathrm{C}$ and $\phi$ to project new values. This process is iterated four times to smooth the solution.

Solution of the velocity field.-Equation (7) is used to predict the change in velocity field. The projected velocity changes are used to calculate viscous stresses that are then used to correct the velocity change.

Solution of the pressure equation.-The velocity changes are fed into the pressure Poisson equation that is solved by successive over relaxation to produce a uniform static pressure field consistent with our incompressible flow assumption. 


\section{Approximation of the Liquid Jet}

Since the solution of the Navier-Stokes equation we used conserves mass strongly, injecting liquid into the solution space posses many difficulties. To avoid these problems the entering jet was modeled as a recirculating region where the axial velocity was forced to a desired value. This allowed the radial velocity to entrain liquid into the jet and thus conserve mass. A $0.5 \mathrm{~cm}$ length for this region was chosen since this appeared to be long enough so at the top of the region the mass entrainment was sufficient such that the $\mathrm{v}$ velocity was the dominant fluid motion.

\section{Prior Work}

\section{Laminar Model Runs of Test Cases}

Chato $^{33}$ used this code to model the drop tower runs of Aydelott. ${ }^{19}$ Little of the drop tower film remains, but figure 1 shows the time history of test $15(\operatorname{Re}=450$, Fill level $50 \%$ ). Times are estimated from frame counts since the clock is out of focus. The best match with Aydelott's data were found to be the laminar tests with Reynolds number of 450. Four tanks were used in Aydellott's test a $10 \mathrm{~cm}$ diameter Cylindrical tank with hemispherical ends $20 \mathrm{~cm}$ long including the endsable 1); a similar tank with the end opposite the inlet inverted (labeled b); the same as the second except with ring slosh baffles at the 30 and $77 \%$ full levels(labeled c); and a $10 \mathrm{~cm}$ sphere. Only results for the tanks labeled $\mathrm{b}$ and $\mathrm{c}$ are shown since tank a was never run at $450 \mathrm{Re}$, and the spherical tank could not be modeled without curved boundaries Figure 2 shows the computer model of test 15 . Table 1 contains the key features of these tests

TABLE 1.-EXPERIMENTAL RESULTS OF AYDELOTT

\begin{tabular}{|c|c|c|c|c|c|}
\hline Test & $\begin{array}{c}\text { Tank } \\
\text { shape }\end{array}$ & $\begin{array}{c}\text { Liquid } \\
\text { fill } \\
\text { vol\% }\end{array}$ & $\begin{array}{c}\text { Jet } \\
\text { Reynolds } \\
\text { no. }\end{array}$ & $\begin{array}{c}\text { Jet } \\
\text { Weber } \\
\text { no. }\end{array}$ & $\begin{array}{c}\text { Ratio of } \\
\text { Geyser } \\
\text { height to } \\
\text { tank } \\
\text { diameter }\end{array}$ \\
\hline 12 & $\mathrm{~b}$ & 39 & 450 & .49 & .36 \\
\hline 15 & $\mathrm{c}$ & 50 & 450 & .39 & .42 \\
\hline 50 & $\mathrm{~b}$ & 60 & 450 & .37 & .24 \\
\hline 64 & $\mathrm{~b}$ & 91 & 480 & .31 & .10 \\
\hline
\end{tabular}

Visual Comparison.-Comparison of the data to the model show similarity in jet spread and flow motion. The model even captures the vortex shedding from the tip of the geyser as the flow develops although the axisymetric nature of the model forces more regularity in the vortex shedding than is seen in the drop tower film.

Predicted Geyser Height. - Model predictions of geyser heights are shown in table 2. For comparison the measured heights of Aydelott are shown.
TABLE 2.-GEYSER HEIGHTS FOR LAMINAR RUNS

\begin{tabular}{|c|c|c|}
\hline Test & $\begin{array}{c}\text { Model ratio } \\
\text { of Geyser height } \\
\text { to tank radius }\end{array}$ & $\begin{array}{c}\text { Measured ratio } \\
\text { of Geyser height } \\
\text { to tank radius }\end{array}$ \\
\hline 12 & 0.22 & 0.36 \\
\hline 15 & 0.1 & 0.42 \\
\hline 50 & 0.1 & 0.24 \\
\hline 64 & 0.1 & 0.10 \\
\hline
\end{tabular}

\section{Parametric Studies}

Once the code's performance against the experimental cases has been established, the code was used to understand the parameters and influences that lead to the geyser shapes observed. Several parameters which where not studied in the experiment where selected for further analysis (actually most of these parameters would be quite difficult to vary experimentally but can be changed easily by computer.) Computer runs were made and the results analyzed. Findings are reported below

\section{Contact Angle}

The first parameter to be studied was the effect of changing wall contact angle. This value can be changed with a single input into the code. It is of interest because it varies greatly in the liquids used in spacecraft (water 60 degrees, cryogens 0 degrees). It also gives a range of free surface forces (90 degrees no force, 0 degrees maximum force.) This change enables us to study how changes in the equilibrium shape without the jet influence the final geyser shape.

Free surface shapes are plotted in figures 3 to 5 for various contact angles for a jet of $17 \mathrm{~cm} / \mathrm{s}$ at 3.10 seconds with a liquid fill height of $6.5 \mathrm{~cm}$. Figure 6 shows a comparison between the shapes. The 30 degree contact angle acts to raise the free surface by only $0.02 \mathrm{~cm}$ over the 0 degree geyser height. The 60 degree contact angle raises slightly more about $0.12 \mathrm{~cm}$ from the 0 degree mark. The 90 degree contact angle increases the geyser height by 0.19

Although the geyser heights increase they are not directly proportional to the change in equilibrium free energy. It can be shown that the equilibrium free surface radius of a tank with a finite contact angle is a spherical segment of a sphere of larger radius. Hence it should be the same as that of a larger tank with a smaller contact angle.

One factor that may reduce the geyser height with increasing contact angle is the change in liquid volume. In order to obtain the same fill height at the center line and match the equilibrium free surface shape the liquid volume for the 30,60, and 90 contact angles had to be reduced. Table 1 shows fluid volumes for each test. Since the total quantity of liquid is fixed, in order for the geyser to rise liquid in the outer regions of the tank must draw 
down. To estimate the shift in level from this effect the liquid interface shape was compared to the equilibrium free surface. Geyser volume was estimated by taking the volume of liquid above the equilibrium line in the center of the tank. Liquid draw down was estimated by the volume of gas below the equilibrium free surface. These two volumes are tabulated in table 5 and 1 .

TABLE 3.-VOLUME COMPARISIONS

\begin{tabular}{|c|c|c|c|}
\hline $\begin{array}{c}\text { Contact angle } \\
\text { (degrees) }\end{array}$ & $\begin{array}{c}\text { Total liquid } \\
\text { volume } \\
\text { (Cubic cm) }\end{array}$ & $\begin{array}{c}\text { Geyser } \\
\text { volume }\end{array}$ & $\begin{array}{c}\text { Draw down } \\
\text { volume }\end{array}$ \\
\hline 0 & 637.8 & 0.64 & 1.80 \\
\hline 30 & 609.2 & 1.4 & 2.12 \\
\hline 60 & 560.9 & 1.5 & 4.78 \\
\hline 90 & 510.5 & 2.06 & 7.2 \\
\hline
\end{tabular}

In theory the two quantities should be exactly equal, in practice the liquid draw down is greater. Calculation of total volume based on free surface position shows some loss in total fluid volume as the calculation progresses. Evaluation of the total color function shows no change so the fluid must be lost in the spreading of the color function at the interface. Because the delta volumes at the interface are small volumes compared to the total volume they are much more influenced by this inaccuracy. A small volume loss of less than $1 \%$ can result in a tripling of the draw down volume. Once the liquid loss is removed from the draw down volume, the geyser volume and draw down volume are seen to match much more closely.

\section{Tank Wall}

The results of the contact angle study suggested a significant influence of the wall on the final geyser height. To further study the influence of the wall, a tank with a radius of $10 \mathrm{~cm}$ was run with the same jet submergence as the $5 \mathrm{~cm}$ tank. The increased distance to the wall should reduce the influence of the wall and result in higher geyser height. Figure 7 shows a comparison in free surface profiles at 3.1 seconds for a $17 \mathrm{~cm} / \mathrm{s}$ jet at liquid height of $6.5 \mathrm{~cm}$ for a 0 degree $5 \mathrm{~cm}$ tank and a 0 degree $10 \mathrm{~cm}$ tank. The larger tank results in a geyser height increase of $0.61 \mathrm{~cm}$. Some of this can be attributed to a decrease free surface energy. The surface pressure of a $10 \mathrm{~cm}$ radius bubble is only 4.48 dynes $/ \mathrm{cm}^{2}$ compared to 8.96 dynes $/ \mathrm{cm}^{2}$ for a $5 \mathrm{~cm}$ radius bubble, a decrease of $50 \%$. Another part of this can be attributed to an increased geyser volume. In order to match the $6.5 \mathrm{~cm}$ at the centerline in the $10 \mathrm{~cm}$ tank liquid volume has increased to $3,114 \mathrm{~cm}^{3}$. This corresponds to a fill fraction of $49.6 \%$ rather than the $39 \%$ of the $5 \mathrm{~cm}$ tank. Geyser volume increases from 0.6 to $39.2 \mathrm{~cm}^{3}$, while draw down volume becomes $41.9 \mathrm{~cm}^{3}$ instead of $1.8 \mathrm{~cm}^{3}$. Also of interest is the crossover point between the geyser and the draw down regions. This is at $7.5 \mathrm{~cm}$, far beyond the $5 \mathrm{~cm}$ wall. This indicates that unconstrained the geyser influence extends beyond the $5 \mathrm{~cm}$ radius. Another comparison which is valuable is to compare to the 60 degree contact angle case. Analysis predicts the equilibrium shape for a $5 \mathrm{~cm}$ tank with a 60 contact angle and that of a $10 \mathrm{~cm}$ tank with a 0 degree contact angle to be identical. Figure 8 shows a comparison of free surface shapes between the $5 \mathrm{~cm}$ and 60 degrees, and the 60 degree equilibrium equivalent radius of $10 \mathrm{~cm}$. Here one can see that the 60 contact angle on a $5 \mathrm{~cm}$ wall has acted to pin the free surface at a $0.2 \mathrm{~cm}$ lower level than would be reached by the $10 \mathrm{~cm}$ case at $5 \mathrm{~cm}$. Also the contact angle formed by the $10 \mathrm{~cm}$ interface at the $5 \mathrm{~cm}$ mark is clearly less than 60 degrees. Hence although the free surface equilibrium shapes are the same the jet deformed shapes are not.

To see the effect of the wall pinning without as much influence from changing free surface geometry a $10 \mathrm{~cm}$ radius tank with a 90 degree contact angle was also run. Figure 9 shows a comparison between the $5 \mathrm{~cm} 90$ degree run and $10 \mathrm{~cm} 90$ degree run. Again the larger tank diameter produces an increase in geyser height. This cannot be attributed to the decrease in free surface energy since the 90 contact angle provides no pressure across the interface. Draw down level does not seem to be important either since both cases draw down level is about the same. However it appears that the $5 \mathrm{~cm}$ wall prevents the jet from expanding as much as it would like.

\section{Surface Tension}

In order to study a broad range of free surface shapes without changing the flow field significantly, it was decided to parametricly vary the surface tension. Physically this is a bit unrealistic since surface tension is a fixed function of the test fluids thermodynamics and cannot be arbitrarily selected. However if one looks at the dimensionless quantities of Reynolds number and Weber number (which were shown in prior chapters to be the key dimensionless quantities governing geyser formation), Surface tension is the only parameter in the Weber number which can be changed without changing the Reynolds number as well. This makes the parametric investigation of surface tension a powerful tool for the investigation of the effect of the free surface on the geyser process while holding the bulk flow field constant. Table 4 lists Surface Tension, Weber number, geyser and draw down volumes.

TABLE 4.- RESULTS FOR SURFACE TENSION CHANGES
\begin{tabular}{|c|c|c|c|c|}
\hline $\begin{array}{c}\text { Surface } \\
\text { tension } \\
\text { dynes/cm }\end{array}$ & $\begin{array}{c}\text { Weber } \\
\text { no. }\end{array}$ & $\begin{array}{c}\text { Geyser } \\
\text { height } \\
\mathrm{cm}\end{array}$ & $\begin{array}{c}\text { Geyser } \\
\text { volume } \\
\mathrm{cm}^{3}\end{array}$ & $\begin{array}{c}\text { Draw } \\
\text { down } \\
\text { volume } \\
\mathrm{cm}^{3}\end{array}$ \\
\hline 5.6 & 1.96 & 16.7 & 15.1 & 17.1 \\
\hline 11.2 & 0.98 & 8.90 & 18.0 & 17.2 \\
\hline 16.8 & 0.65 & 7.19 & 4.43 & 5.96 \\
\hline 22.4 & 0.49 & 6.88 & 0.64 & 1.80 \\
\hline 44.8 & 0.25 & 6.79 & 2.81 & 3.7 \\
\hline
\end{tabular}


Figure 10 shows a comparison of free surface shapes for different values of surface tension after 3.1 seconds of flow. As expected unbounded geyser growth occurs at a Weber number of about 1 where the flow force just starts to exceed the surface tension forces. Figure 15 shows axial velocity profiles for each of the runs at $6 \mathrm{~cm}$ from the tank bottom. They are almost indistinguishable indicating the validity of our assumption that the bulk flow is mostly unaffected by surface tension. Figure 16 shows the radial velocity flows at $0.6 \mathrm{~cm}$ from the centerline (about the edge of the Jet at a height of $6 \mathrm{~cm}$ from the bottom) here marked differences become apparent. The first is the shift in radial jet location caused by free surface motion. The second is that free surface deformation seems to broaden the radial outflow jet but reduce the peak magnitude. The Table 5 shows the mass flow balances for each jet.

TABLE 5.-MASS BALANCE FOR SURFACE TENSION VARIATION

\begin{tabular}{|c|c|c|}
\hline Surface tension & $\begin{array}{c}\text { Mass flow in } \\
\text { (Axial flux at } \\
6 \text { cm from the } \\
\text { bottom) }\end{array}$ & $\begin{array}{c}\text { Mass flow out } \\
\text { (Radial flux at } \\
0.6 \text { cm from the } \\
\text { centerline) }\end{array}$ \\
\hline 5.6 & 3.65 & 1.89 \\
\hline 11.2 & 3.65 & 3.40 \\
\hline 16.8 & 3.65 & 3.19 \\
\hline 22.4 & 3.65 & 3.00 \\
\hline 44.8 & 3.65 & 4.03 \\
\hline
\end{tabular}

At the lowest surface tension the mass flow out of the jet region is much smaller than the mass entering supporting our finding of unstable jet growth. Looking at our three stable cases free surface deformation seems to broaden the radial outflow jet but reduce the peak magnitude.

\section{Summary of Results}

Parametric investigation produced several interesting finding. Investigation of the contact angle showed the expected trend of increasing contact angle increasing geyser height. Investigation of the tank radius showed some interesting effects and demonstrated the zone of free surface deformation is quite large. These finding may call into question the assumption of Aydellot ${ }^{19}$ that a $5 \mathrm{~cm}$ radius tank is large enough that the wall has little effect on geyser height. Variation of the surface tension with a laminar jet showed clearly the evolution of free surface shape with Weber number. Its predicted breakthrough is a Weber number of 1 as opposed to 1.73 found for the experimental results showing the influence that turbulent jet spreading has on decreasing geyser height.

\section{References}

1. Bentz, M.D., et al. "Tank Pressure Control Experiment - A Low-g Mixing Investigation," AIAA 90-2376.

2. Bentz, Michael D., "Tank pressure control in low gravity by jet mixing," NASA-CR-191012, March 1993.

3. Bentz, M.D., Knoll, R.H., Hasan, M.M., Lin, C.S., "Low-g fluid mixing - Further results from the Tank Pressure Control Experiment" AIAA PAPER 932423, June 1993.

4. Hasan, Mohammad M., Lin, Chin S., Knoll, Richard H., and Bentz, Michael D., "Tank Pressure Control Experiment: Thermal Phenomena,” NASA TP 3564, March 1996.

5. Bentz, Michael D., et al. "Tank Pressure Control Experiment - Results of three space flights," AIAA Paper 97-2816, July 1997.

6. Chato, D.J. and Martin, T.A.., "Vented Tank Resupply Experiment - Flight Test Results," AIAA 97-2815, July 1997.

7. Jacqmin, D. "Calculation of Two-Phase NavierStokes Flows Using Phase-Field Modeling" Journal of Computational Physics 155, 96-127, 1999.

8. Symons, E.P., Nussle, R.C., and Abdalla, K.L. "Liquid Inflow to Initially Empty, Hemispherical Ended Cylinders During Weightlessness" NASA TN D 4628: June 1968.

9. Symons, Eugene P., Nussle, Ralph C., "Observations of Interface Behavior During Inflow to an Elliptical Ended Cylinder in Weightlessness," NASA TM X-1719, January 1969.

10. Symons, Eugene P. "Interface Stability During Liquid Inflow to Initially Empty Hemispherical Ended Cylinders in Weightlessness," NASA TM X-2003, April 1970.

11. Symons, Eugene P., Staskus, John V., "Interface Stability During Liquid Inflow to Partially Full, Hemispherical Ended Cylinders in Weightlessness," NASA TM X-2348, August 1971.

12. Staskus, John V., "Liquid Inflow into a Baffled Cylindrical Tank During Weightlessness," NASA TM X-2598, August 1972.

13. Spuckler, Charles M. "Liquid Inflow to Initially Empty Cylindrical Tanks in Low Gravity," NASA TMX-2613, August 1972.

14. Labus, T.L., Aydelott, J.C., Andracchio, C.R., "Effect of Baffles on Inflow Patterns in Spherical Containers During Weightlessness," NASA TMX-2670, November 1972. 
15. Symons, Eugene P., "Effect of Throttling on Interface Behavior and Liquid Residuals in Weightlessness," NASA TM X-3034, May 1974.

16. Aydelott, J.C. "Axial Jet Mixing of Ethanol in Spherical Containers During Weightlessness," NASA TM X-3380: April 1976.

17. Labus, Thomas L., "Liquid Jet Impingement Normal to a Disk in Zero Gravity," NASA TP 1017, August 1977.

18. Aydelott, J.C. "Axial Jet Mixing of Ethanol in Cylindrical Containers During Weightlessness," NASA TP-1487: July 1979.

19. Aydelott, J.C.: "Modeling of Space Vehicle Propellant Mixing” NASA TP-2107: January 1983.

20. Concus, P., "Capillary Stability in an Inverted Rectangular Tank," Adv. Astro. Sc. Vol. 14, pp. 21-37, 1963.

21. Concus, P., "Static Menisci in a Vertical Right Circular Cylinder," J. Fluid Mech. Vol 34, part 3 pp. 481-495, 1968.

22. Nickell, R.E., Tanner, R.I., Caswell, B. "The solution of viscous incompressible jet and free surface flows using finite element methods" J. Fluid Mechanics vol. 65, part 1, pp. 189-206, 1974.

23. Hochstein, J.I., Gerhart, P.M., Aydelott, J.C., Computational Modeling of Jet Induced Mixing of Cryogenic Propellants in Low-G, AIAA 84-1344.

24. Hochstein, J.I. "Computational Modeling of Jet Induced Mixing in Cryogenic Propellant Tanks in Low-G," Ph.D. Thesis, The University of Akron, 1984.
25. Aydelott, J.C., et al., "Numerical Modeling of OnOrbit Propellant Motion Resulting from an Impulsive Acceleration," NASA TM-89873, 1987.

26. Der, J.J., Stevens, C.L., Low-Gravity Bubble Reorientation in Liquid Propellant Tanks, AIAA 87-0622, January 1987.

27. Tegart, James, "Three-Dimensional Fluid Interfaces in Cylindrical Containers" AIAA 91-2174, June 1991.

28. Brakke, K.A. "Surface Evolver Manual" Minimal Surface Team of the Geometry Supercomputer, Available via ftp at geom.umn.edu.

29. Brackbill, J.U., Kothe, D.B., Zemach, C., "A Continuum Method for Modeling Surface Tension," Journal of Computational Physics v100 n2, June 1992.

30. Schrader, G.B. and Hochstein, J.I., "Modeling of Jet-Induced Geyser Formation in Low-Gravity," AIAA 93-0256, January 1993.

31. Van der Waals, J.D., The Thermodynamic Theory of Capillarity Flow Under the Hypothesis of a Continuous Variation of Density (Verhandel/Konink. Akad. Weten., 1893), Vol 1; English Translation, Journal of Statistical Physics Vol. 20.

32. Cahn, J.W. and Hillard, J.E., "Free Energy of Nonuniform Systems. III. Nucleation in a TwoComponent Incompressible Fluid," Journal of Chemical Physics V31 n3, September 1959.

33. Chato, David J. "Influence of Turbulence on The Restraint of Liquid Jets By Surface Tension In Microgravity," AIAA 2002-0758, January 2002. 


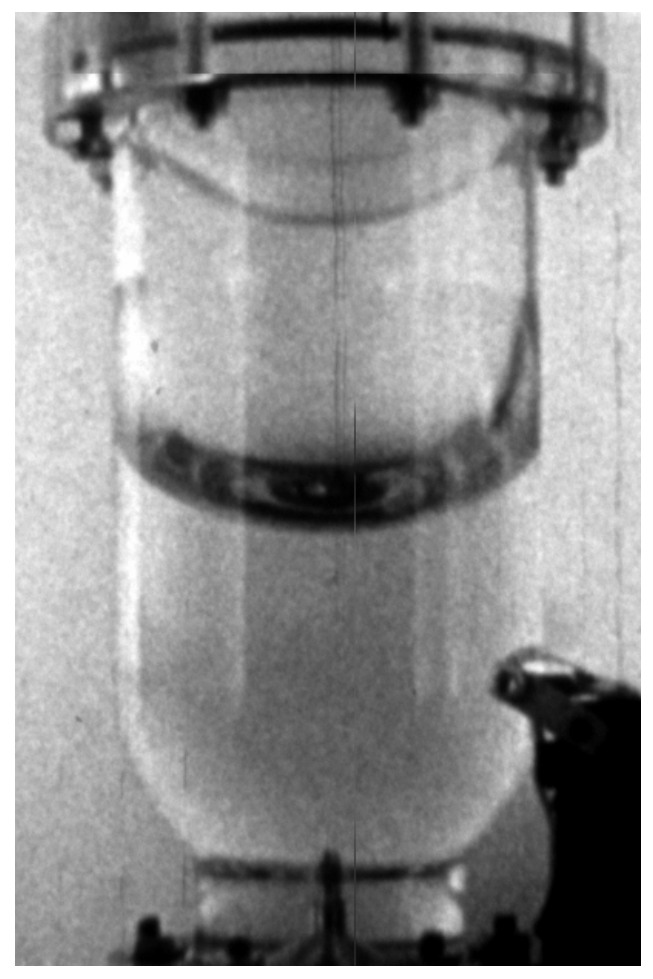

a) Start

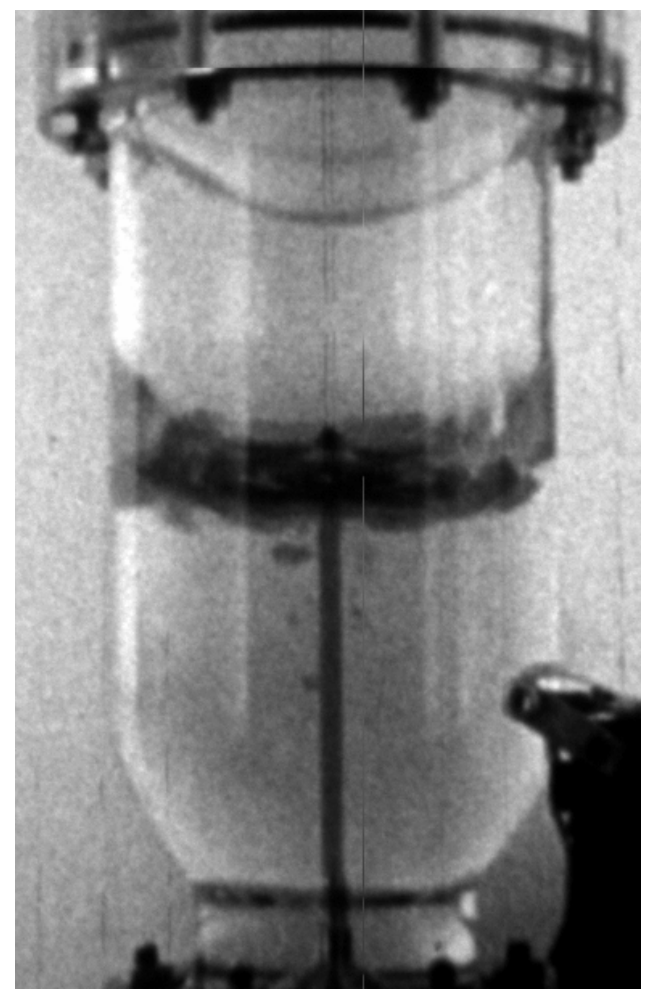

c) 2.04 seconds

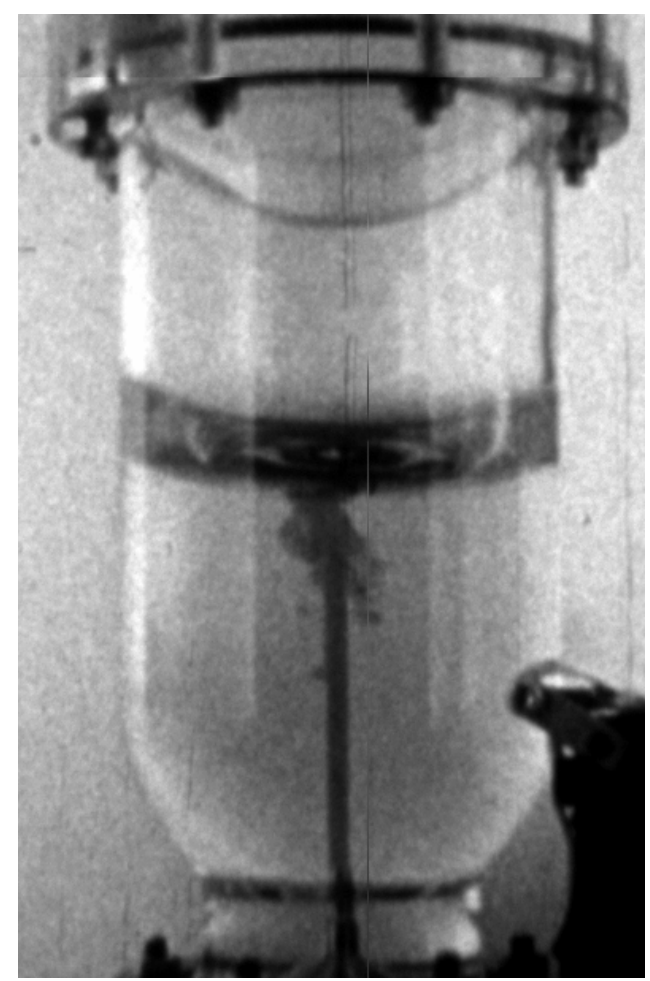

b) 0.93 seconds

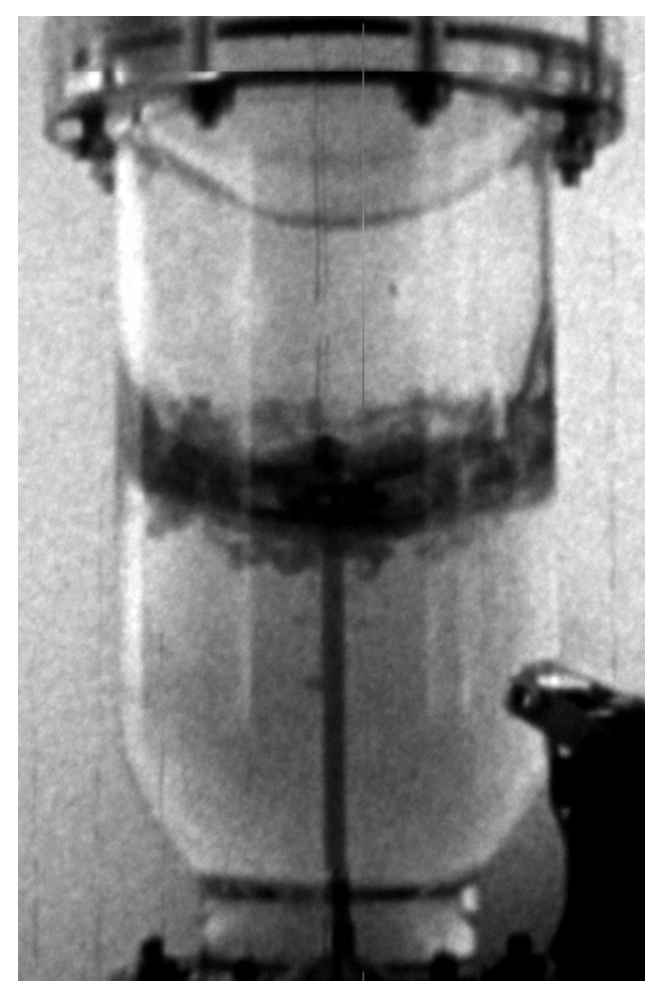

d) 3.10 seconds

Figure 1.-Drop Tower Run 15 Fill 50\% Jet Velocity $17 \mathrm{~cm} / \mathrm{s}$. 

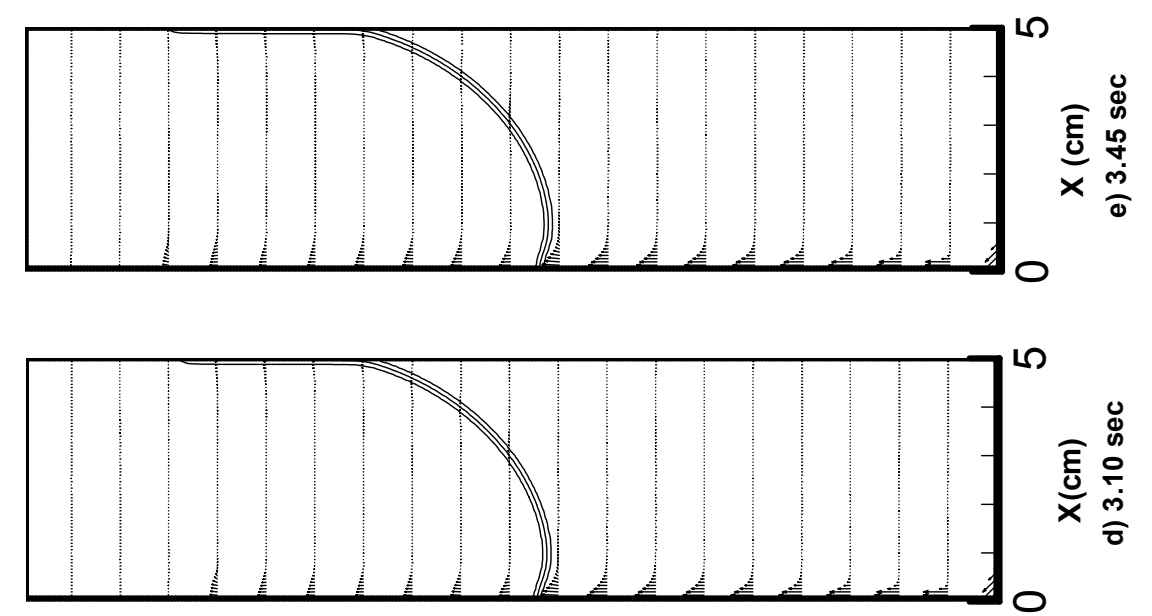

हี่
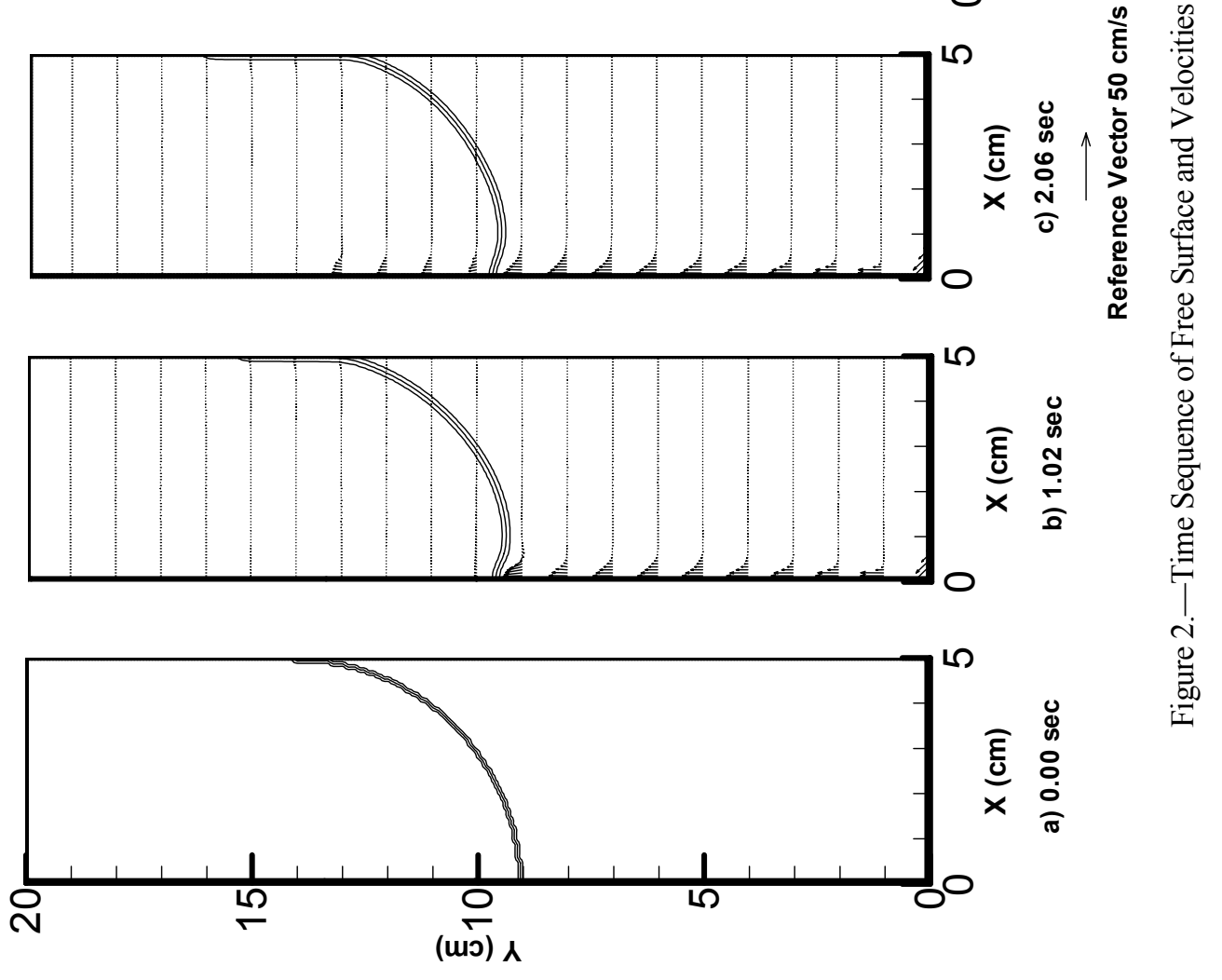


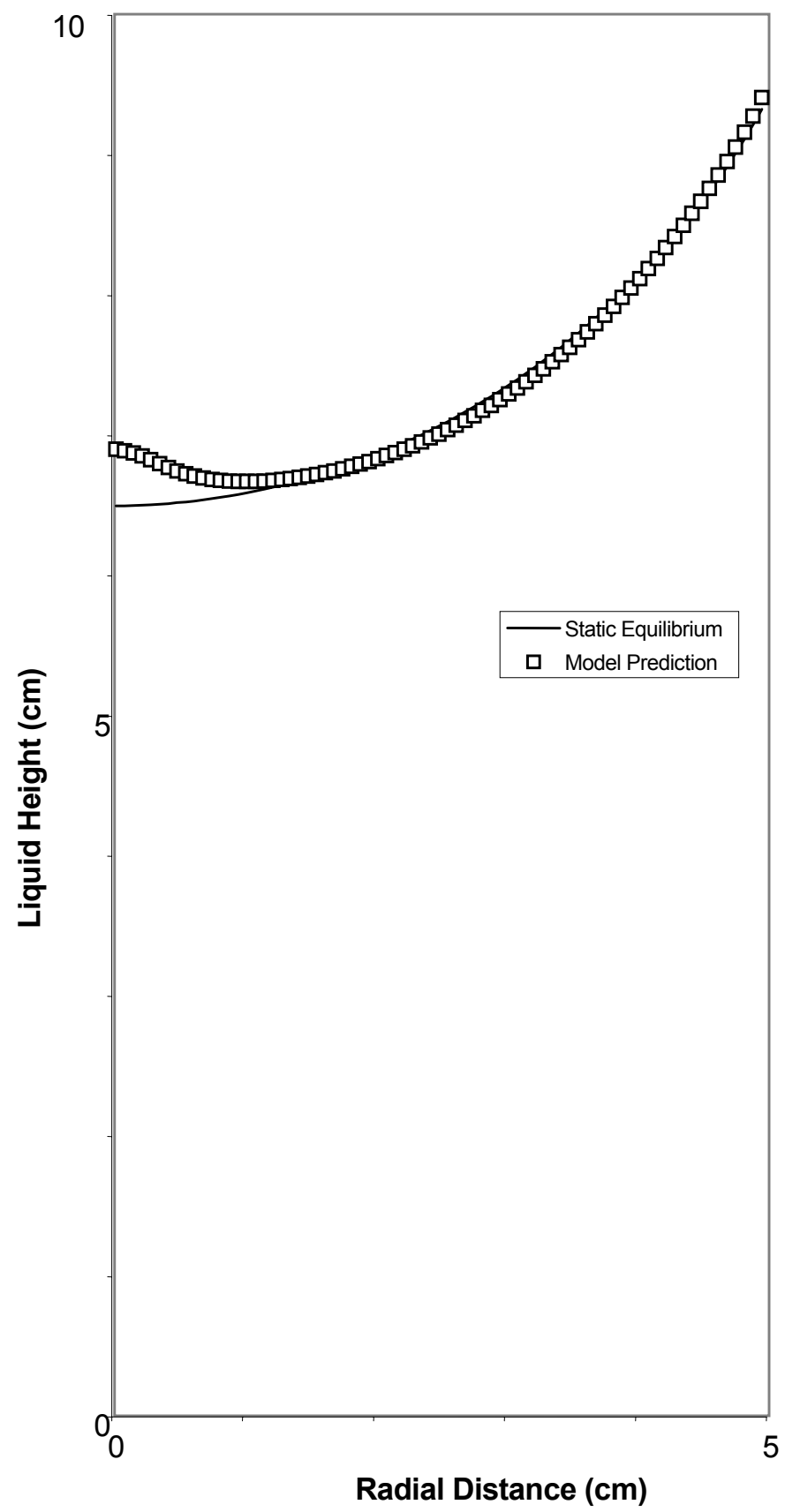

Figure 3.-Free surface Shape 30 degree contact angle Time 3.1 seconds. 


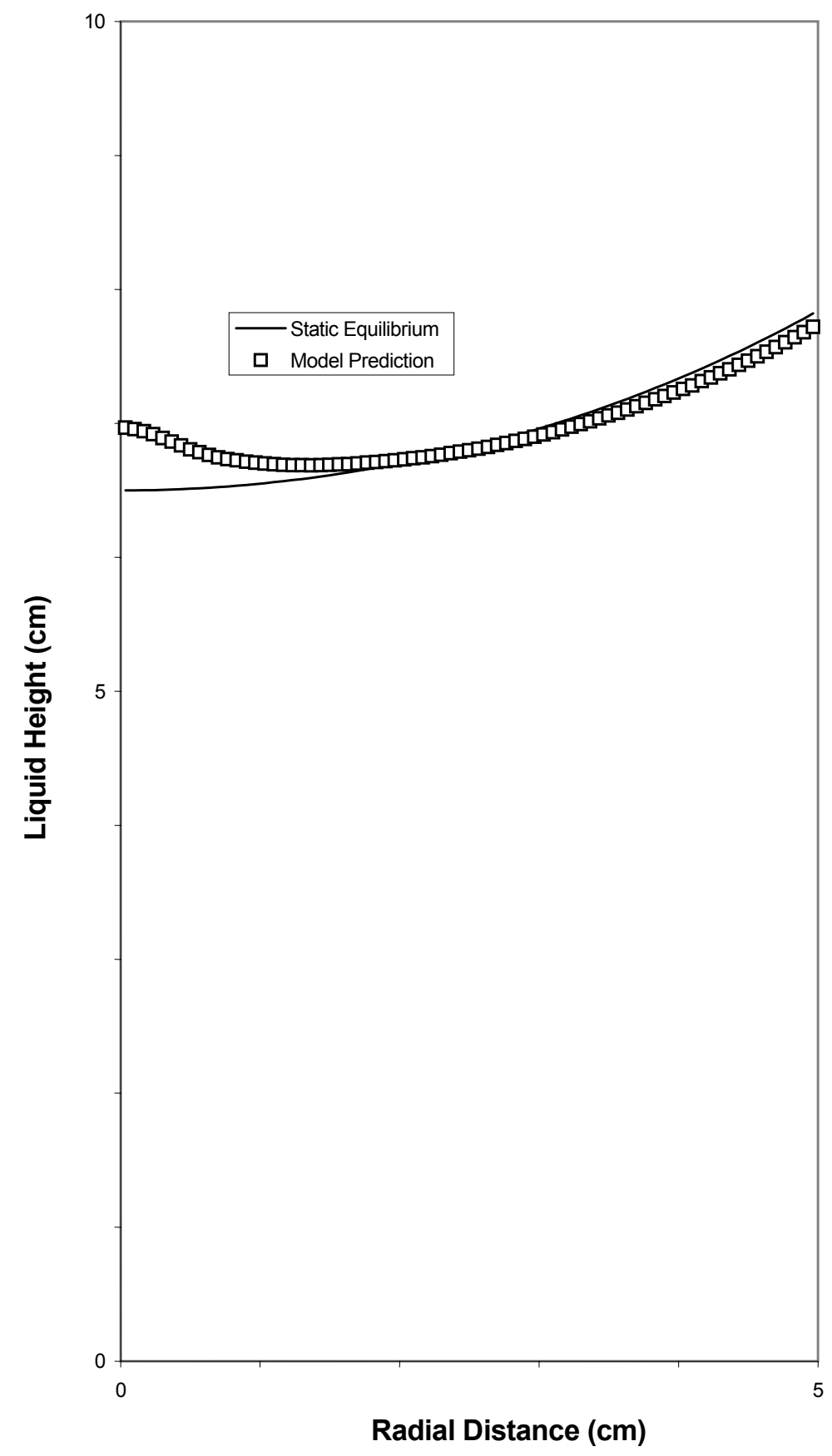

Figure 4.-Free Surface Shape 60 degree contact angle. 


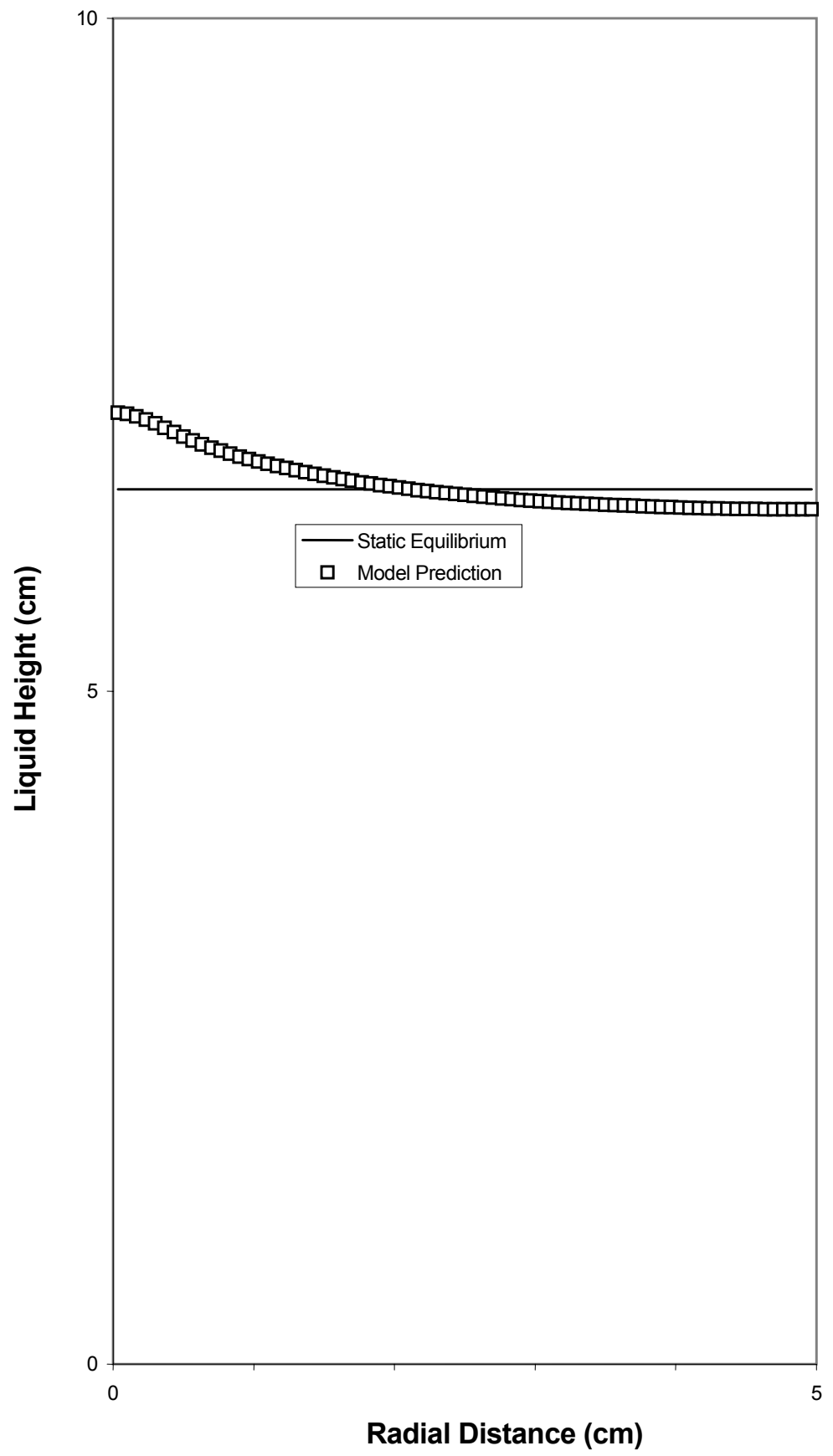

Figure 5.-Free Surface Shape 90 degree contact angle. 


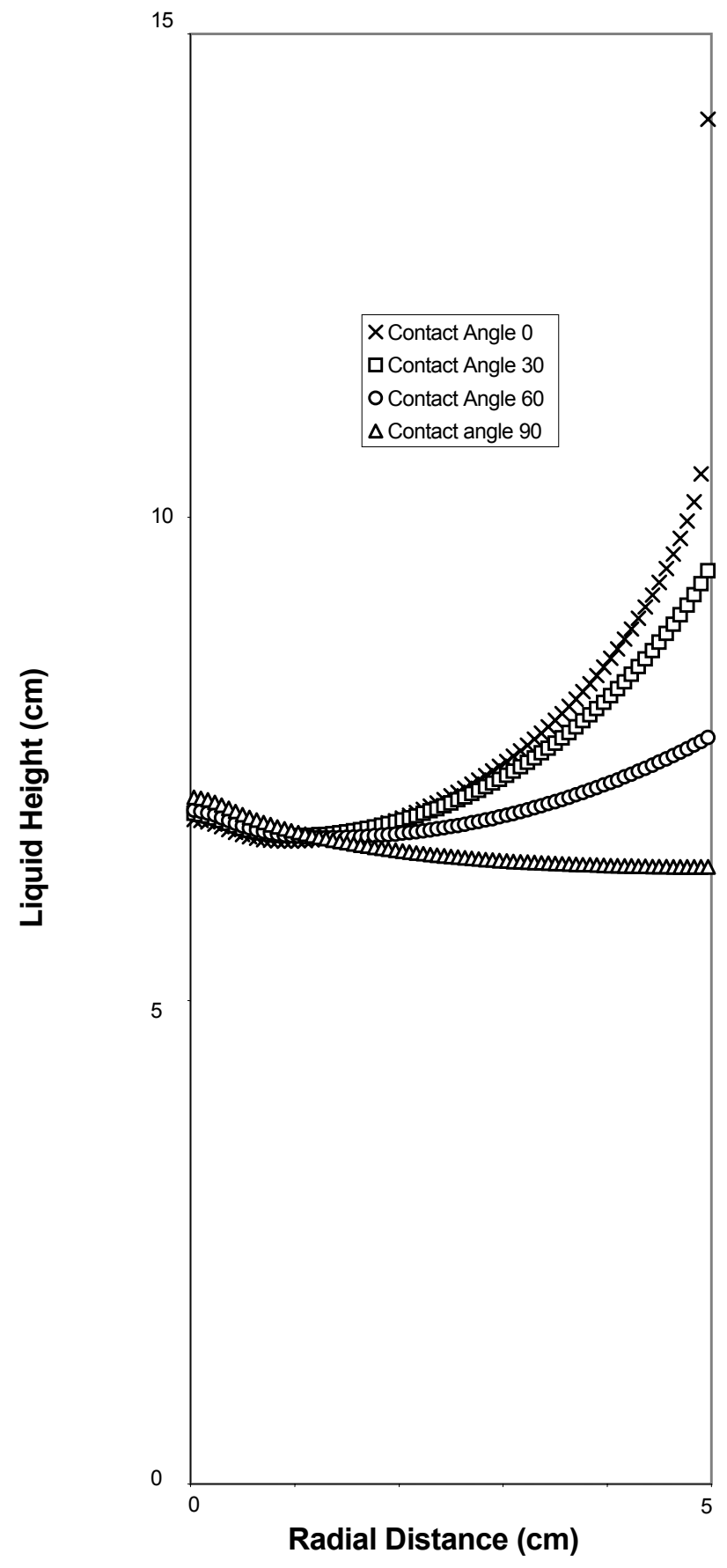

Figure 6.-Comparison of Free surface Shape as a Function of Contact Angle. 


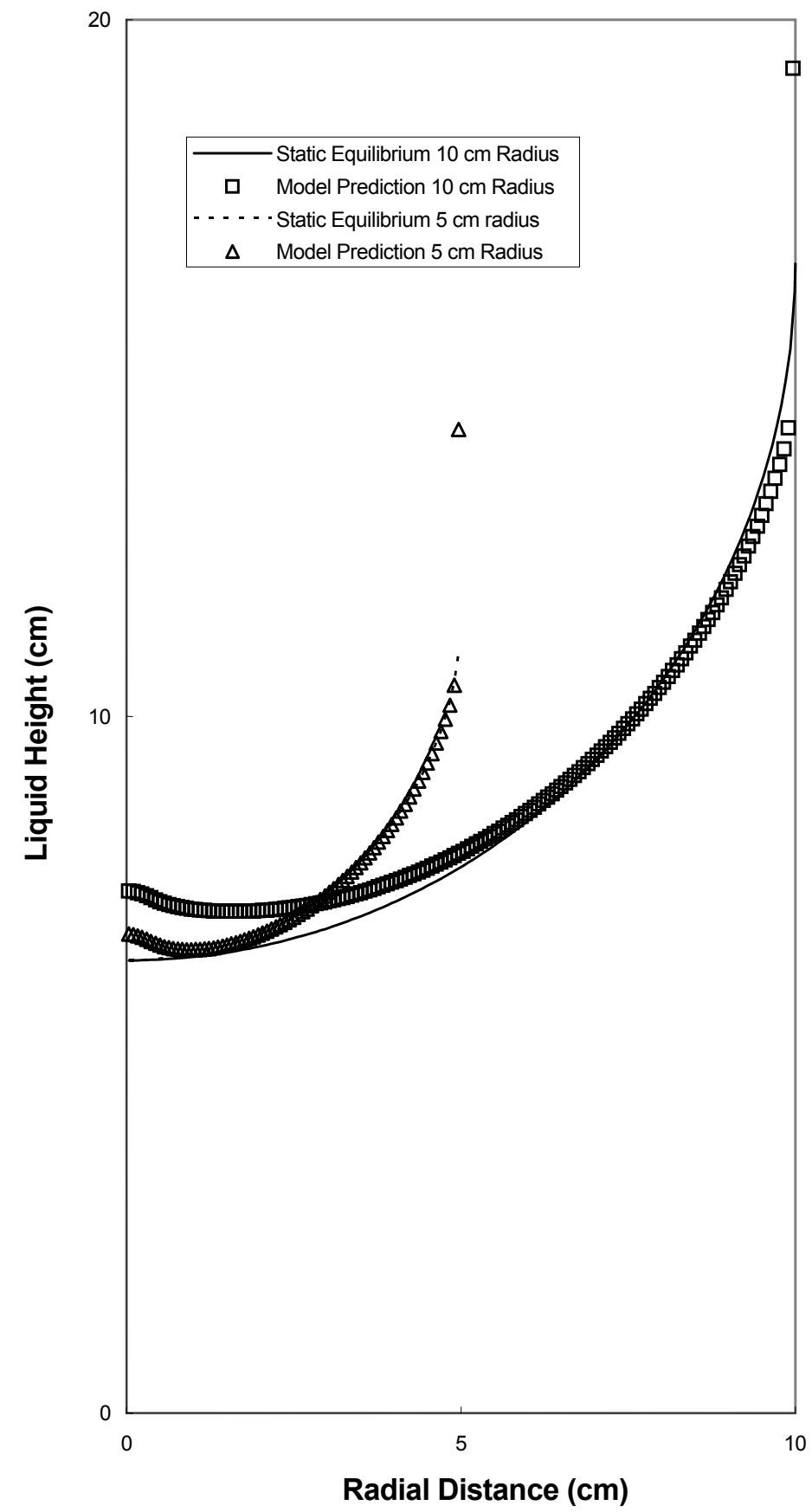

Figure 7.-Free Surface Shape Comparison for Tanks of Different Raduis. 


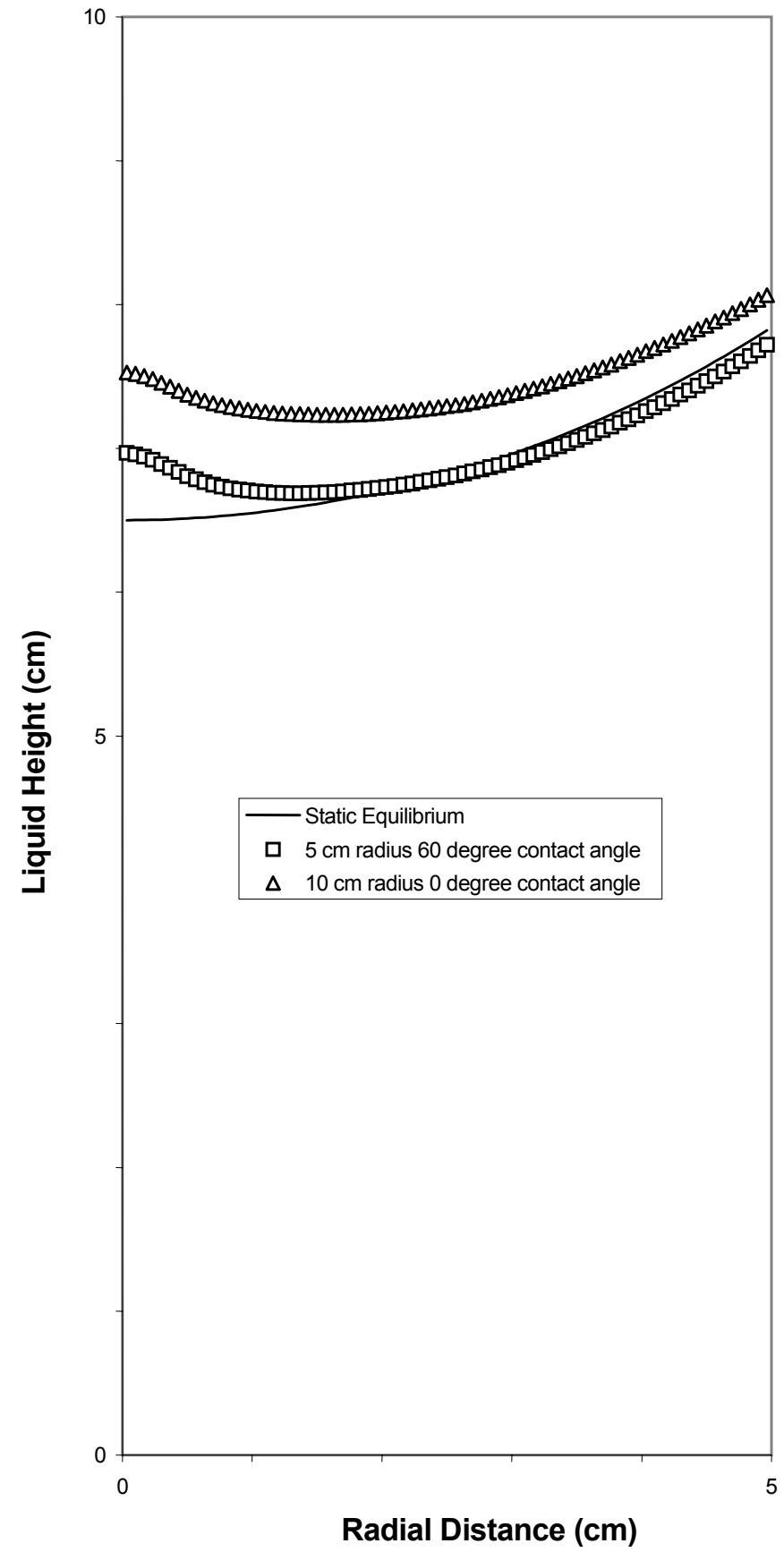

Figure 8. Comparision of Free Surface Shapes between a Tank of $10 \mathrm{~cm}$ radius with 0 degree contact angle and a Tank of $5 \mathrm{~cm}$ radius with a 60 degree contact angle (same ideal free surface shape). 


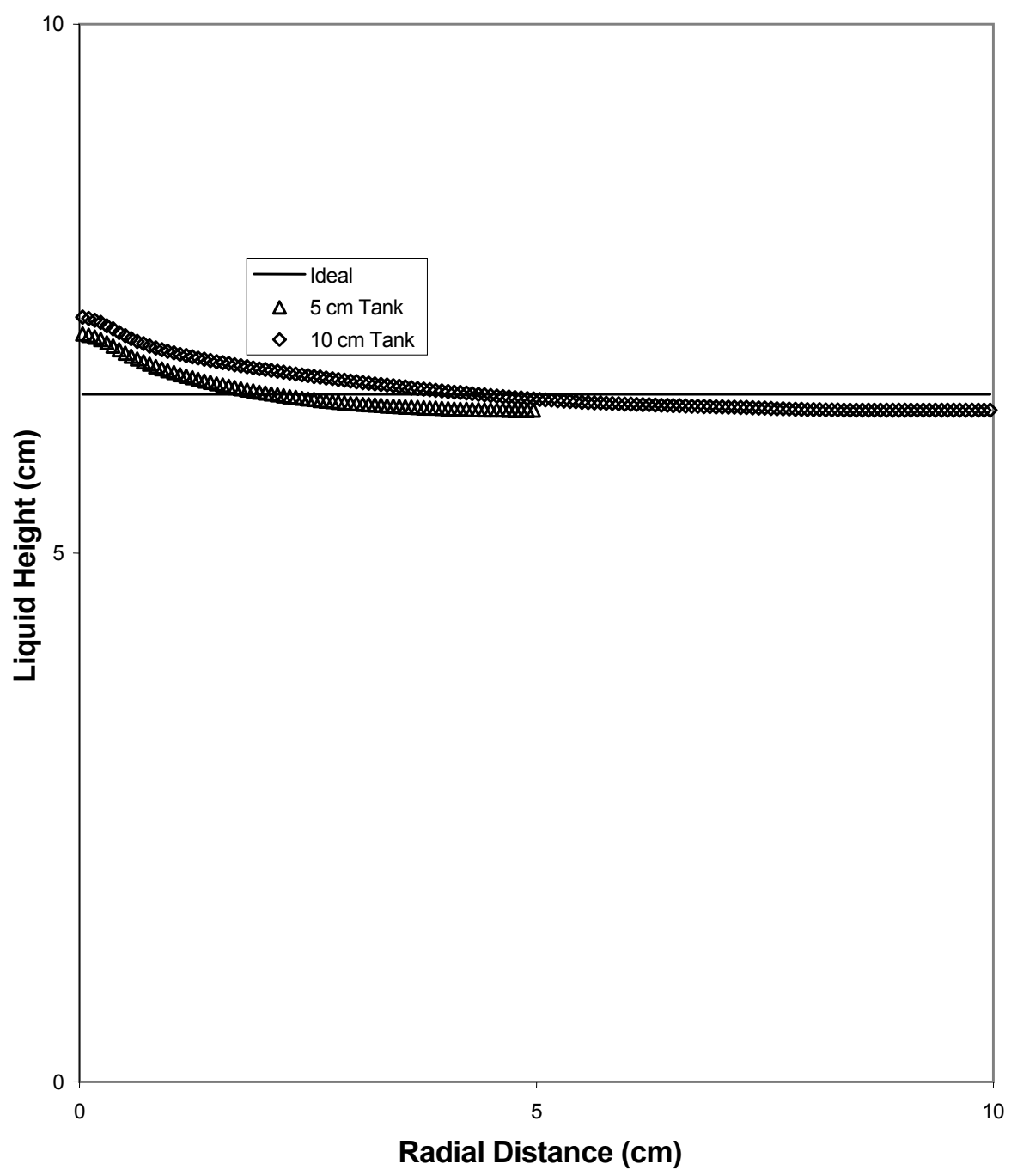

Figure 9.-Free Surface Shape comparison between $5 \mathrm{~cm}$ and $10 \mathrm{~cm}$ Radius Tanks with 90 degree contact angles. 


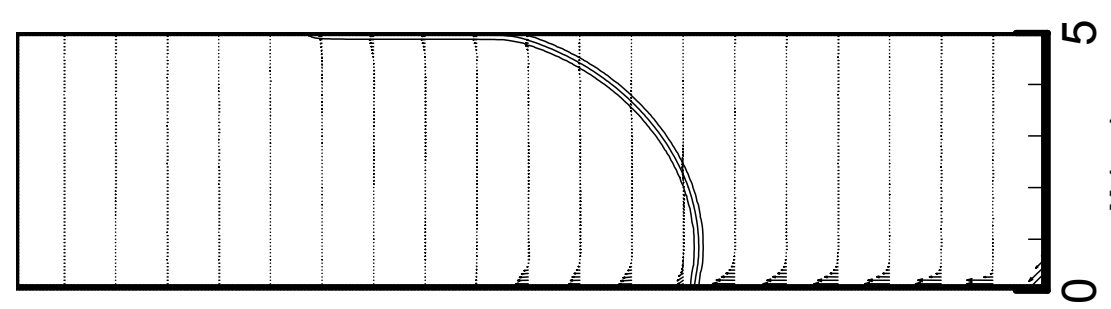

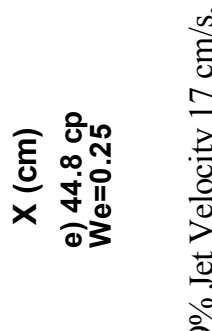
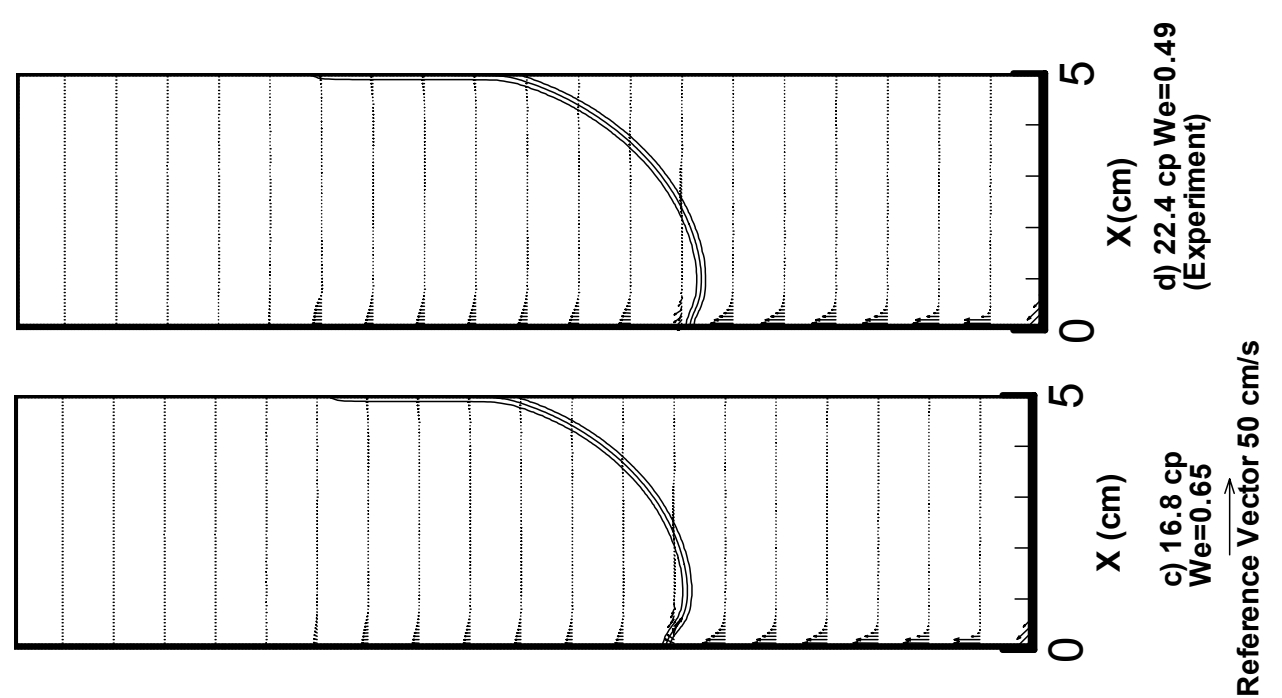

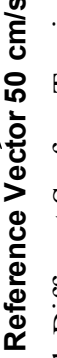

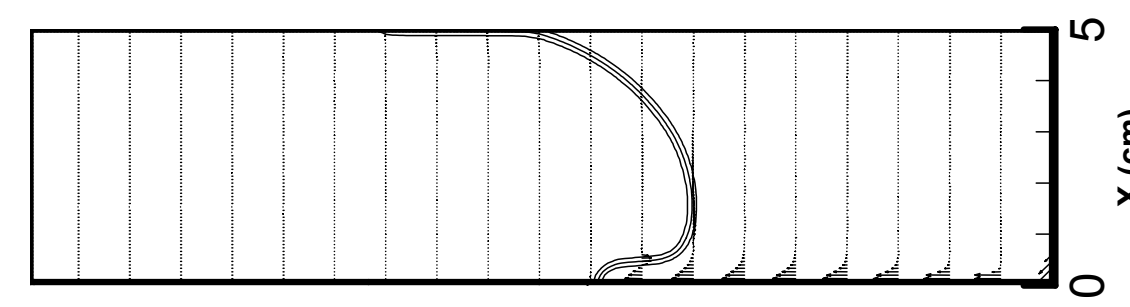

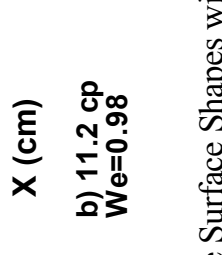

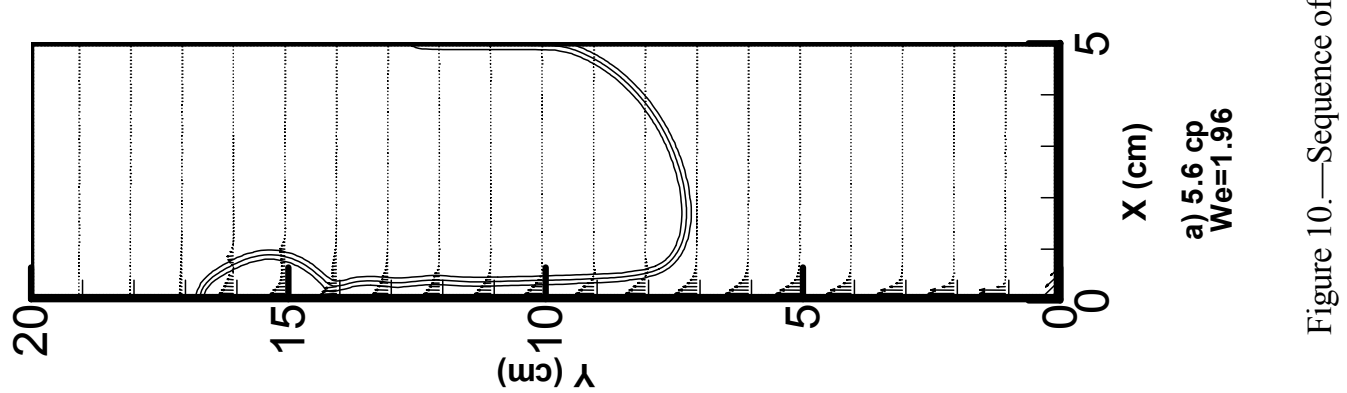




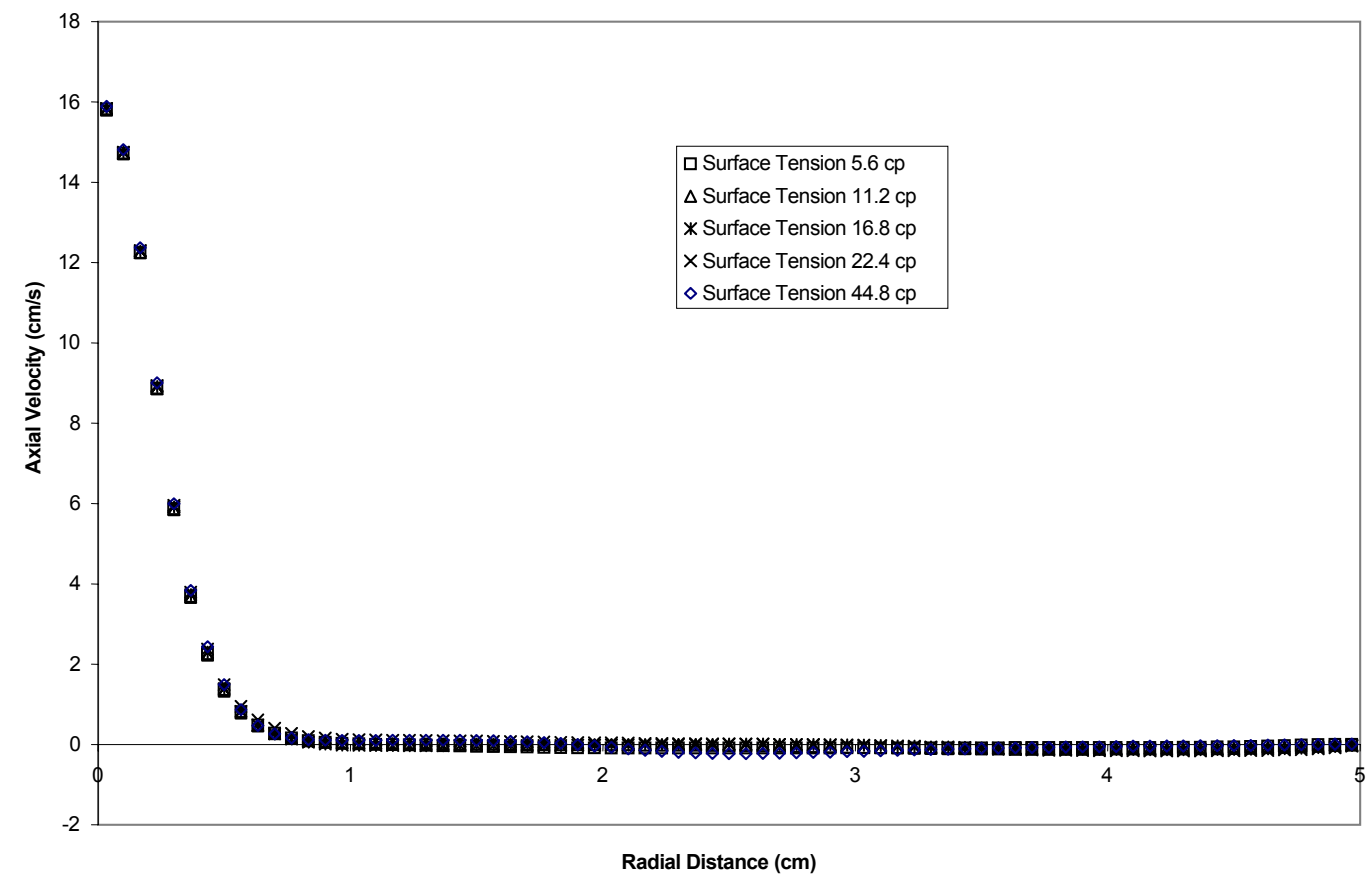

Figure 11.-Axial Velocity at $6 \mathrm{~cm}$ from Tank Bottom.

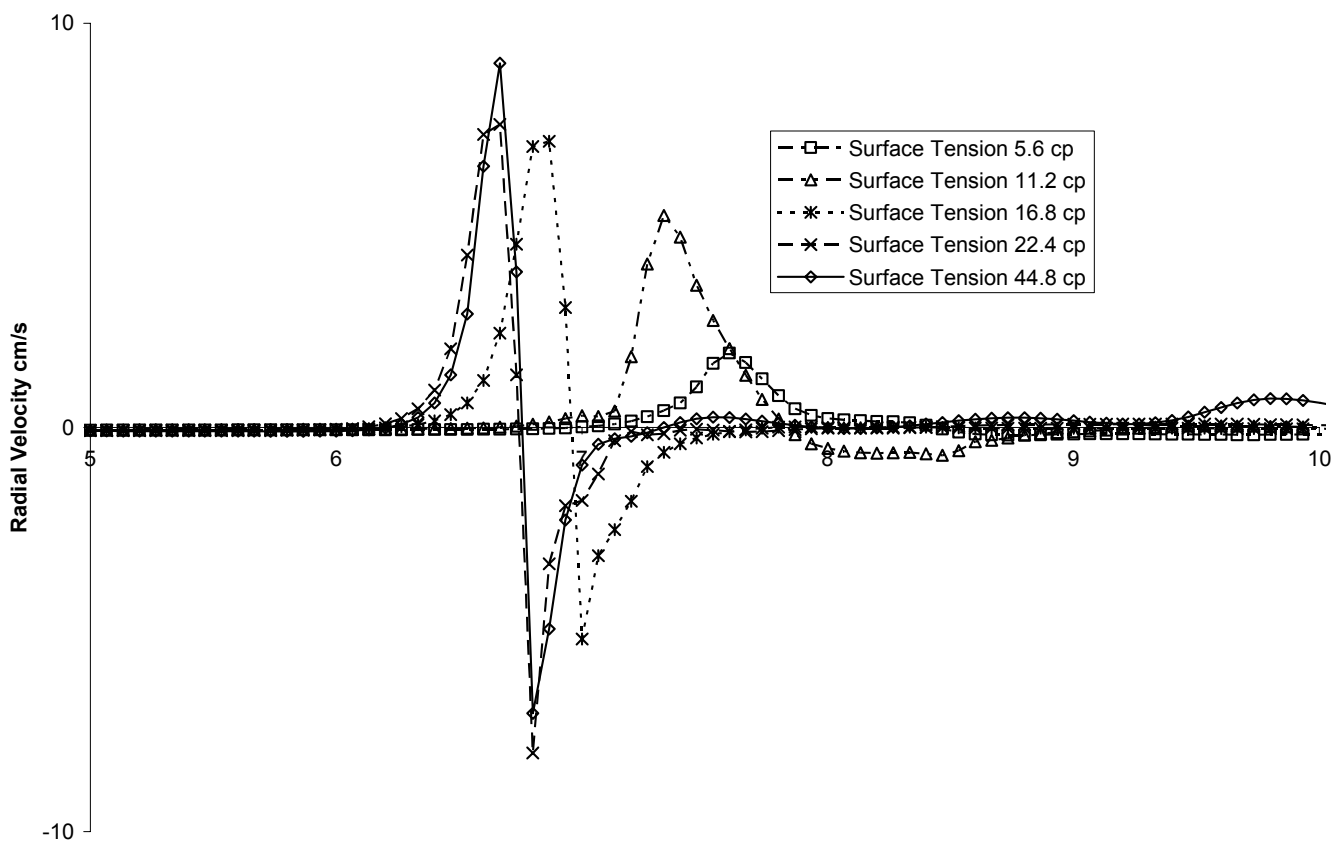

Distance from Tank Bottom (cm)

Figure 12.- Radial Velocity at $0.6 \mathrm{~cm}$ from Centerline. 


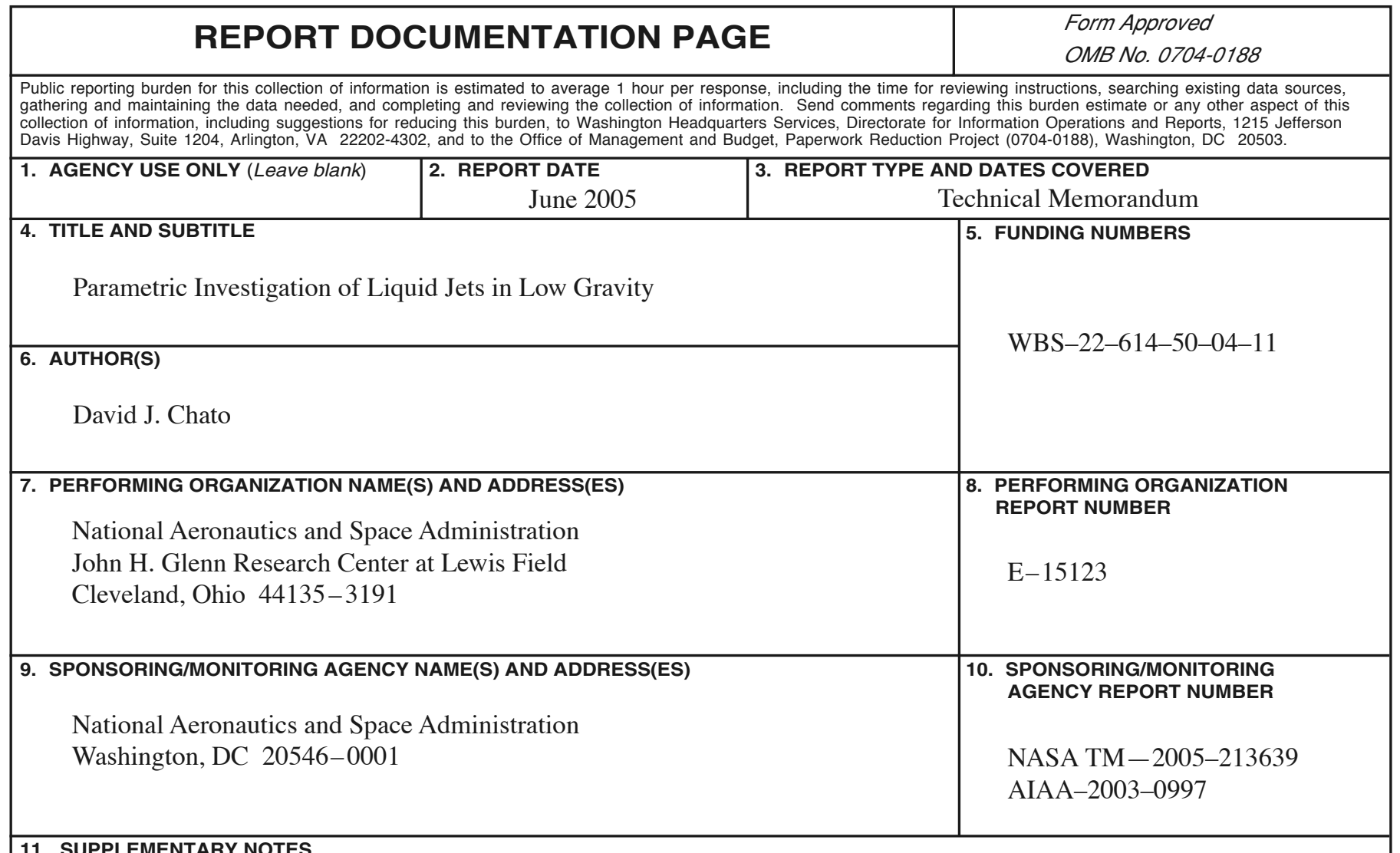

\section{SUPPLEMENTARY NOTES}

Prepared for the 41st Aerospace Sciences Meeting and Exhibit sponsored by the American Institute of Aeronautics and Astronautics, Reno, Nevada, January 6-9, 2003. Responsible person, David J. Chato, organization code RTP, 216-977-7488.

\begin{tabular}{l|l}
\hline 12a. DISTRIBUTION/AVAILABILITY STATEMENT & 12b. DISTRIBUTION CODE \\
Unclassified - Unlimited & \\
Subject Category: 34 & \\
Available electronically at http://gltrs.grc.nasa.gov & \\
This publication is available from the NASA Center for AeroSpace Information, 301-621-0390. &
\end{tabular}

\section{ABSTRACT (Maximum 200 words)}

An axisymetric phase field model is developed and used to model surface tension forces on liquid jets in microgravity. The previous work in this area is reviewed and a baseline drop tower experiment selected for model comparison. This paper uses the model to parametrically investigate the influence of key parameters on the geysers formed by jets in microgravity. Investigation of the contact angle showed the expected trend of increasing contact angle increasing geyser height. Investigation of the tank radius showed some interesting effects and demonstrated the zone of free surface deformation is quite large. Variation of the surface tension with a laminar jet showed clearly the evolution of free surface shape with Weber number. It predicted a breakthrough Weber number of 1 .

\begin{tabular}{|c|c|c|c|}
\hline 14. SUBJECT TERMS & & & $\begin{array}{c}\text { 15. NUMBER OF PAGES } \\
24\end{array}$ \\
\hline NSN 7540-01-280-5500 & & & $\begin{array}{l}\text { andard Form } 298 \text { (Rev. 2-89) } \\
\text { scribed by ANSI Std. Z39-18 } \\
-102\end{array}$ \\
\hline
\end{tabular}



